\title{
The coming of age: Aged residential care nursing in Aotearoa New Zealand in the times of COVID-19
}

\author{
Frances Hughes ${ }^{1}$, PhD, RN, Clinical Director, Oceania, Auckland \\ Anna Blackwell 2, PGDip, RN, Nursing Director/Owner, Cook Street \\ Nursing Care Centre, Palmerston North \\ Tanya Bish, MN(Hons), BCom, RN, Clinical Director, Metlife Care, \\ Auckland \\ Cheyne Chalmers, MMgt, RN, Chief Operating Officer, Ryman Healthcare, \\ Christchurch \\ Katherine Foulkes, PGDip, RN, Clinical Services Director, Bupa, Auckland \\ Lynda Irvine, RN, Head of Clinical Services, Summerset Group Holdings
}

Citation

Hughes, F. A., Blackwell, A., Bish, T., Chalmers, C., Foulkes, K., Irvine, L., Robinson, G., Sherriff, R., \& Sisson, V. (2021). The coming of age: Aged residential care nursing in Aotearoa New Zealand in the times of COVID-19. Nursing Praxis in Aotearoa New Zealand, 37(3), 25-29. https://doi.org.10.36951/27034542.2021.030

Gillian Robinson, BN, RN, Director, Health Care Compliance Solutions Ltd, Christchurch

Rhonda Sherriff, RN, Managing Director, Chatswood Retirement Village, Christchurch

Virginia Sisson, PGCert, RN, Operations Manager, The Selwyn Foundation, Auckland

\author{
All authors from Aotearoa New Zealand \\ Corresponding Authors: ${ }^{1}$ frances.hughes@oceaniahealthcare.co.nz; 2 cookstncc@gmail.com;
}

\begin{abstract}
For years aged care nursing has been largely overlooked and marginalised from mainstream healthcare. COVID-19 brought both aged residential care and nursing into sharp focus for Aotearoa New Zealand. This paper provides a commentary on the work of executive nurses within the Nursing Leadership Group of the New Zealand Aged Care Association as COVID-19 spread into some ARC facilities in early 2020 and threatened the health and wellbeing of many residents and nurses. The group influenced the agenda and implementation of policies for Aged Residential Care and brought the voice of nursing and residents of aged care to the forefront at national and regional levels.
\end{abstract}

Keywords: aged residential care; COVID-19; leadership; nursing; nursing homes

\section{Introduction}

The COVID-19 pandemic brought aged residential care (ARC) nursing into sharp focus across Aotearoa New Zealand. The first positive case of COVID-19 in a rest home was on 22 March 2020 (Ministry of Health, 2020) just three weeks after the first confirmed case. The aged care sector was on high alert due to the impact of COVID-19 on older adults being reported internationally. By March 2020, D’Adamo et al. (2020) were outlining the high mortality rates from COVID-19 in America and providing insights for ARC settings.

This article reflects the experience of national nurse leaders in the ARC sector during the early months of the global pandemic. The authors of this article are members of the New Zealand Aged Care Association (NZACA) Nursing Leadership Group (NLG) which was formed in December 2019 prior to knowledge of the impending pandemic. The goal of NLG was to represent and advocate for nurses working in the ARC sector and for those vulnerable populations in our care. The ambition of NLG was to increase the profile and encourage greater recognition of registered nurses practicing in ARC facilities. Aged care requires specialised nursing skills and without skilled nursing, quality care outcomes cannot be achieved (Dellefield, 2015; Hughes, 2020). We met for the first time on 22 January 2020 in Wellington as COVID-19 was spreading around the globe and its arrival in Aotearoa New Zealand seemed imminent. Our focus quickly became COVID-19 management in the ARC sector to protect our people and the residents. In this reflective piece we present the role the NLG had in shaping the ARC COVID-19 response in Aotearoa New Zealand, including the challenges 
experienced, learnings for the sector, ongoing work, and opportunities for the future.

Aged residential care beds outnumber acute hospital beds by more than three times (McDougall, 2020). In March 2020, there were approximately 38,000 ARC beds across 670 facilities with an average occupancy level of $87.9 \%$. The ARC sector includes rest homes, secure dementia communities, geriatric/medical hospitals, and psychogeriatric hospital services with an increased number of facilities offering various levels of care to prevent residents having to change facilities if their level of care changes (McDougall, 2020). The population within an ARC facility consists of residents who are very frail and can be clinically unstable; residents who are well but disabled and have very high care needs; residents who have cognitive impairment or mental health issues, with some requiring a secure environment; and residents who are receiving end of life care.

Despite the extensive services the ARC sector provides for older adults, the sector has suffered an image problem for years (Banks, 2018; Colgrave \& Austen, 2016; Montayre, 2015). It is generally not perceived as being part of mainstream health services, which has impacted on the way services, including nursing services were viewed. ARC facilities have not been seen as a place where nurses could flourish while working with autonomy at one's full scope of practice (Colgrave \& Austen, 2016; Cooper et al, 2017). During the COVID-19 response this translated into a lack of understanding by district health boards (DHBs) in relation to not only how ARC systems are structured, but also how nursing care is delivered on a twenty-four-hour, seven day a week basis for this complex and vulnerable population. The NLG found we were spending time helping DHB managers understand the practice setting of an ARC: we are not small wards or hospitals, we are large residential homes where people live - they are not sterile, clinical environments.

The health system was placing different expectations on the ARC sector across the country. District health boards, the Auditor General, and the Ombudsman were undertaking audits to ascertain ARC preparedness for a COVID-19 response particularly pertaining to dementia and psychogeriatric care and personal protective equipment (PPE) supply issues (Hughes, 2020). During this time, we perceived the media were poised to pounce - any resident testing positive for COVID-19 was represented as an ARC sector failure (Lourens, 2020). Where calm, respect, support, and collaboration were needed, there was instead a sense of chaos and fear from within the health sector which was portrayed through the media headlines and articles (Jones, 2020). Despite this, there was a groundswell of strength, pride, and cohesion in the sector. The NLG ARC nursing voice rose up, demanding to be heard, bringing our voice to decision-making whether invited or not. Within the sector there was never a blame mentality in relation to outbreaks, but simply a desire to support and learn more about how to navigate this new threat (Hughes, 2020). Following one of the first facility's experience of a COVID-19 outbreak we invited their clinical services director to join our group, so we could learn quickly what had worked well, what they had learnt, and how we could translate those learnings to be operationalised for ARC nationally.

During COVID-19, the NLG determined the need to step into the void advocating for clinical care in ARC. The NLG became galvanised as we were engaged daily by providers, DHBs, Ministry of Health $(\mathrm{MOH})$ and Public Health Unit (PHU) representatives requesting or generating guidance and advice, which was at times conflicting. We were guided in our experience and knowledge that sound collaboration would result in better outcomes for the residents and staff (Dykgraaf et al., 2021; Kain et al., 2021). Over the initial twelve-week period the NLG played a crucial role not only in representing the ARC providers, but also in representing the needs of older New Zealanders in care. We zoomed daily Monday to Friday (and if necessary, over the weekend) at the end of our 'day jobs.' We learnt quickly how to share documents and edit NZACA or MOH guidance deftly. We provided much needed wellbeing support to each other, and shared resources and expertise. NLG members participated in multiple national forums to represent aged care, at times with politicians, Ministers, MOH officials, and DHB Chief Executive Officers (CEOs). The knowledge, skills, and attributes we held as nurse leaders were tested as these multiple groups were traversed, always ensuring that the residents, whānau, and the people who care for them were at the centre of our thinking, policies, and decision making. We shared with MOH and DHB's our own plans we had produced for our employers, ranging from outbreak plans (which included how to manage in one bubble clients with dementia), mental health material for staff anxiety management and vulnerable staff assessment tools. At one stage 
between us all we were providing advice to over eight national committees, including the Office of the Prime Minister's Chief Science Advisors and the AntiMicrobial Infection and Control Working Group. We also were successful in having a meeting at Parliament with cross party representatives in November 2020 to discuss the issues of ARC nursing and COVID-19 related issues, particularly lobbying for early vaccination access for our residents and staff.

The following captures the main themes of NLG involvement during the initial response and much of this is ongoing.

\section{Advocating and influencing}

Members of NLG became part of multiple $\mathrm{MOH}$ and DHB working groups, ensuring the context of ARC was understood, from small through to large national providers. Advocating for consistency in messaging and ensuring the one source of truth was the $\mathrm{MOH}$. A subgroup met with the MOH regularly to advance codesigned screening tools, and strongly advocating for pre-admission testing. Advocacy work extended beyond healthcare; for example, contact was made with a large grocery chain to challenge a decision determining that aged care workers were not deemed essential workers, yet DHB workers were. Letters were written, phone calls were made, and NLG became vocal in raising the unfair practices that were occurring. During this time, NLG adopted the mantra 'nothing about us without us', ironically a phrase used for many years by marginalised groups wanting a say in how they are governed (Charlton, 1998).

\section{Translation and protection}

As various documents and advice from $\mathrm{MOH}$ were reviewed, emphasis was put on language which was meaningful to the aged care sector. The approaches used and terminology of the DHBs and PHUs were translated into the practice context of ARC. An example was the concept of isolation for those in dementia care communities and the term 'household bubble' was coined in the ARC setting. The group provided critical analysis of evidence and approaches to ensure infection prevention and control guidance for ARC was realistic and operationally feasible. During the 'stocktake' of ARC facilities by the DHB's, we were being asked how we would cohort 'patients' (known in our sector as residents). We had to make it understood that residents reside in their rooms, that it is their own and only space where they have their curios and family photos on their walls, SKY connections, and telephones installed. Rooms are not all the same and it is not reasonable to switch residents around an ARC facility, as hospitals move patients. We emphasised to DHBs, MOH, PHUs that being different didn't make it wrong.

The use of Personal Protective Equipment (PPE) was always on the agenda; what to use when; whether it was appropriate to put masks on residents; how and where to don and doff. Solutions needed to be applied to a variety of different ARC building environments, ranging from small to large, modern to old. We challenged DHBs and the $\mathrm{MOH}$ when views were expressed that ARC's need for PPE was less important than hospital settings.

\section{Logistical operations}

Procurement of PPE and certainty of access should an outbreak occur became a logistical challenge for all in the ARC sector. Supplies normally available became harder to obtain. All the DHBs applied different methodologies to access PPE. NLG shared experiences, suggestions, problem-solved and even donated PPE to those in need. Every DHB had a different process, some seeing the value in working closely with ARC, others seemed to lack the principle of partnership. One of the NLG members went as relief manager into a facility who had most of their staff stood down as close contacts once COVID-19 was detected. She was able to give us daily updates 'from the field' and helped shape our guidance advice to $\mathrm{MOH}$, the NZACA membership, and in our own organisations. Obtaining N95 masks in a site with active COVID was an unexpected difficulty; PPE arriving well expired with gowns and the elastic on masks disintegrating when donned were prime examples of this.

\section{Communications and Quick Thinking}

Critiquing and counterbalancing the inconsistent information that was coming from a variety of sources, particularly DHBs and media (van Beynen, 2020) was a central part of our role. In the early days, predictions of ARC providers becoming morgues was unsettling (Dosa et al., 2020). We focussed on sharing every piece of overseas evidence we found and also brought information from offshore nursing colleagues to learn from to minimise the mass casualties being experienced elsewhere. We received independent advice from a New Zealand microbiologist (Ben Harris) with a specific interest in ARC. We advocated for staff surveillance testing, at 
least daily temperature and oxygen saturation checking for residents, mask wearing for staff, and strict screening of staff and visitors when they returned. Providers developed specific communications for their facilities, for example, psychosocial support material and facility visiting frameworks for clarity.

As International Nurses Day 2020 was celebrated globally, the NLG hosted a webinar for the sector celebrating the role of the aged care nurses. Hundreds of nurses and others connected into this webinar in the middle of the level 4 lockdown. NLG wanted to connect ARC nurses around the country to acknowledge their work, their sacrifices, their fears, and their commitment to each other and the vulnerable residents in ARC care. As leaders we witnessed first-hand the ARC workforce step up, become surrogate family when our doors suddenly shut in March 2020 and all physical contact with their whānau ceased. These staff members lived in fear of taking COVID-19 home to their own families, or inadvertently bringing it into the facility. An already stretched workforce, ARC staff worked above and beyond to keep facilities full of joy and laughter, step into activity roles, be conduits for families, while often juggling reduced family income with their partners not able to work. Staff reported keeping their children at home from school longer just to be sure they didn't bring COVID-19 home. They willingly had invasive nasal swabs whenever they got a hint of cold or flu symptoms. It was a wonderful opportunity to acknowledge some of this on the International Day of the Nurse.

The leadership role that each member played nationally, regionally, and within our own facilities cannot be understated. Many phrases were coined during this time. Our focus was on 'doing the right thing not, necessarily being right.' This resonated with Greenhalgh (2020) recognising that in the face of a pandemic the search for perfect evidence may be the enemy of public good. NLG never had a sense of panic, we supported each other and never judged those who had outbreaks. Knowing the precarious nature of what was occurring, professional support and empathy with those providers was unconditional. Relationships, professional respect, and evidence-based practice have proved critical in the ARC COVID-19 response. Ongoing engagement continues as we worked to advocate for early vaccination, have vaccination mandates, and the current urgent need for boosters for our vulnerable population and workforce. N95 fit testing is high on NLG's radar as is the workforce crisis. The value of the strong leadership and the NLG ARC nursing voice 'came of age' during 2020 and we are continuing to build on these gains.

\section{References}

Banks, S. (2018). The social dynamics of devaluation in an aged care context. Journal of Sociology, 54, 167-177. https://doi.org/10.1177/1440783318766144

Charlton, J. (1998). Nothing about us without us: Disability, oppression and empowerment. University of California Press.

Colgrave, J., \& Austen, K. (2016). Changing clinical education and stamping out the stigma. Australian Nursing and Midwifery Journal, 23(7), 52.

Cooper, E., Splisbury, K., McCaughan, D., Thompson, C., Butterworth, T., \& Hanratty, B. (2017). Priorities for professional development of registered nurses in nursing homes: A Delphi study. Age and Ageing, 46, 3945. https://doi.org/10.1093/ageing/afw160

D’Adamo, H., Yoshikawa, T., \& Ouslander, J.G. (2020). Coronavirus disease 2019 in geriatrics and long-term care: The ABCDs of COVID-19. Journal of the American Geriatrics Society, 68, 912-917. https://doi.org/10.1111/igs.16445

Dellefield, M. (2015). The relationship between registered nurse and nursing home quality: An integrative review (2008 - 2014). Nursing Economics, 33, 95-108.

Dosa, D., Jump, R., La Plante, K., \& Gravenstein, S. (2020). Long-term care facilities and the coronavirus epidemic: Practical guidelines for a population at highest risk. Journal of the American Medical Directors Association, 21, 569-571. https://doi.org/10.1016/j.jamda.2020.03.004

Dykgraaf, S. H., Matenge, S., Desborough, J., Sturgiss, E., Dut, G., Roberts, L., McMillan, A., \& Kidd, M. (2021). Protecting nursing homes and long-term care facilities from COVID-19: A rapid review of international evidence. Journal of the American Medical Directors Association, 22(10), 1969-1988. https://doi.org/10.1016/j.jamda.2021.07.027

_Greenhalgh, T. (2020, May 28). Will evidence-based medicine survive COVID-19? Boston Review. https://bostonreview.net/articles/trisha-greenhalghcovid-19-and-evidence-based-medicine/

Hughes, F. (2020). Reflections of a nursing leader during an extraordinary time of aged care in New Zealand. Journal of Gerontological Nursing, 46(12), 3-6. https://doi:org/10.3928/00989134-20201106-01

Jones, N. (2020, April 14) Covid 19 coronavirus: 'Safe practice' issues at Rosewood Resthome in Christchurch after deadly virus struck. NZ Herald. https://www.nzherald.co.nz/nz/covid-19coronavirus-safe-practice-issues-at-rosewood- 
resthome-in-christchurch-after-deadly-virusstruck/BOWY56K6W3D6MGP3F2DMTW4S2E/

Kain, D., Stall, N., Brown, K., McCreight, L., Rea, E., Kamal, M., Brenner, J., Verge, M., Davies, R., \& Johnstone, J. (2021). A longitudinal, clinical, and spatial epidemiologic analysis of a large COVID-19 long-term care home outbreak. Journal of the American Medical Directors Association, 22, 2003-2008.

https://doi.org/10.1016/i.jamda.2021.07.021

Lourens, M. (2020, June 11). Rosewood resthome, NZ's deadliest Covid-19 cluster, breached obligations. Media report. Stuff.

https://www.stuff.co.nz/national/health/coronavirus $\not 121791737 /$ rosewood-rest-home-nzs-deadliestcovid19-cluster-breached-obligations

McDougall, J. (2020). Aged residential care industry profile 2019 - 20. New Zealand Aged Care Association.

https://nzaca.org.nz/wp-

content/uploads/2020/08/ARC-Industry-Profile2019-20-Final.pdf
Ministry of Health. (2020). Independent review of COVID-19 clusters in aged residential care facilities. Author.

https://www.health.govt.nz/publication/independent -review-covid-19-clusters-aged-residential-carefacilities

Ministry of Health. (2020, February 28). Author. https://www.health.govt.nz/news-media/mediareleases/single-case-covid-19-confirmed-new-zealand

Montayre, J. (2015) Negativity surrounds aged-care nursing. Kai Tiaki Nursing New Zealand 21(10), 27.

van Beynen, M. (2020, May 2) Inside Rosewood: The rest home with over half of NZ's Covid-19 deaths. Stuff. https://www.stuff.co.nz/thepress/news/121333615/inside-rosewood-the-resthome-with-over-half-of-nzs-covid19-deaths

Funding: None

Conflict of interest: None 